LUXIÉRNAGA

Perla Nieves Puga Peña 


\section{El concepto de libertad en J-P Sartre y su actualidad en las sociedades contemporáneas}

\section{Introducción: La libertad definida por Sartre}

En este artículo se revisará el concepto de libertad de Jean-Paul Sartre, así como su permanencia en las sociedades contemporáneas. Esto mediante la definición que Sartre da a conocer en el contexto del existencialismo, en el cual se demuestra que la naturaleza del ser humano es ser libre en esencia. Para ello partiremos de la definición de libertad ofrecida por Sartre, quien, a su vez, indica que se compone de dos momentos: primero, desde la subjetividad del individuo y segundo, la responsabilidad que se tiene frente al otro y que por eso se habla acerca de una libertad social.

También consideramos el cómo es que la libertad se ve limitada, a partir de la influencia de las instituciones, y se encargan de enajenar al individuo en las sociedades contemporáneas. Contra ello Sartre propone la emancipación con la unión de los individuos hacia el grupo, mediante la revolución.

\section{El pensamiento existencialista de Sartre:}

Para entender el pensamiento de Sartre es necesario dividirlo en dos etapas fundamentales: La fenomenológica y la existencialista. La primera, es su fase de formación, en la cual, estudia a Husserl y de él retoma sus ideas para su orientación, en sus estudios fenomenológicos, los cuales se reflejan en sus obras filosóficas y literarias, además, en esta etapa adquiere las ideas para entender la vida, en la cual posteriormente, descubre a la conciencia como todo lo que nos hace ser humanos y también se da cuenta que somos 'fenómenos ontológicos' que dependen completamente de la reflexión filosófica. 
En su segunda etapa, la existencialista Sartre representa principalmente el núcleo de sus ideas y de sus obras fundamentales, en ellas defiende que en 'el ser humano la existencia precede a la esencia', es decir, "el humano es aquel que se hace, se realiza $y$, por tanto, no hay una naturaleza humana previa, y en consecuencia el hombre es libre y se construye por medio de sus decisiones y acciones". ${ }^{1}$

La existencia misma, para Sartre, representa el punto de partida para el ser humano en el que su libertad brota ya que es el único ser que es capaz de captar su existencia de manera consciente, y solo por ello es que puede hacer de él lo que él quiera.

Sartre pertenece a la escuela de los existencialistas ateos, por lo que sostiene que no hay tal existencia de un Dios que rija, o determine, la forma de vida o incluso las decisiones que se van tomando de ella, por lo que, el hombre es el único responsable, en este sentido, los actos y las decisiones determinan lo que somos, el ser humano es su propio constructo, por eso no necesita que un ser supremo que lo determine, he aquí que la existencia precede a la esencia, que significa que cada individuo, al ser un ser completamente consciente de sí mismo, actúa de forma independiente.

Una pregunta que Sartre se hace en El existencialismo es un humanismo es; "¿Qué significa aquí que la existencia precede a la esencia?, significa que el hombre empieza por existir, se encuentra, surge en el mundo y después se define". ${ }^{2}$ En este sentido, no hay tal esencia humana que nos defina como tal, porque antes de nacer es sólo nada y sólo mediante su propia construcción es que se define su esencia.

\section{El concepto de libertad definida por Sartre}

Para Sartre, la libertad de los individuos no está determinada; es decir, en el momento que el hombre nace, es libre, por lo tanto, sin el sustento de algo exterior a él, se convierte en su propia responsabilidad, y es dueño de la idea de crearse a sí mismo,

\footnotetext{
${ }^{1}$ Sartre, Jean- Paul. (1990). El existencialismo es un humanismo, México, ediciones Quinto Sol, p. 22.

2 Íbid p. 10.
} 
esto con base en su realidad y posibilidades propias. En este sentido, el hombre empieza por existir, surge en el mundo y posteriormente se define, así tenemos que después de existir se puede concebir como él quiera.

En este sentido la existencia se manifiesta como mera contingencia, es decir, puede o no ser, por lo que, "por definición la existencia no es una necesidad [...], ya que no hay conciencia sin objeto que solo puede ser reconocida por esta que en su comprensión se sabe a sí misma como existente". ${ }^{3}$ Esto significa que la conciencia humana es la que se convierte, sobre todo, en esta posibilidad de llegar a ser, porque el camino lo va construyendo en base a las decisiones que toma.

Para Sartre: "La naturaleza del ser se divide en dos aspectos ontológicos: el primero es el "«ser para sí» que es posible por la conciencia y la libertad del individuo y efectúan el ente a la persona", ${ }^{4}$ la conciencia se crea a sí misma por medio de sus elecciones. En este sentido es que, por medio de la posibilidad de conciencia, es que somos seres libres que nos enfrentamos a una realidad en la que debemos tener presentes nuestras limitaciones y, a partir de ello, construir nuestra propia esencia.

El hombre crea una esencia que debe construir a lo largo de su vida, desde el primer momento que nace, por eso, "para ser totalmente libre de determinaciones, lo primero que Sartre debe abolir es la propia esencia”.

Por eso, Laura G. Álvarez-Valdés, señala que la conciencia es todavía un proyecto que no ha sido completado o realizado, ya que hay algo que de cierta manera le imposibilita llegar a ser lo que quiere, es mera posibilidad de llegar a ser, ya que la conciencia llega sólo a ser existencia sin esencia, la conciencia insertada en el hombre es la que lo lleva verdaderamente a poder ser en el mundo. ${ }^{6}$

En consecuencia, cuando ya se tiene conciencia de sí mismo, es el hombre quien llevará a cabo las riendas de su vida, ya que no es responsabilidad de nadie más,

\footnotetext{
${ }^{3}$ Rodríguez García J. L. (2015). Sartre: El hermoso orgullo de ser libre, Lectulandia, p. 42.

4 Sartre, Jean- Paul (2004) El ser y la nada, Argentina, editorial Losada.

5 Sartre, Jean- Paul (1990) El existencialismo es un humanismo, Op. Cit, p. 22.

${ }^{6}$ Cfr. Gordillo Álvarez-Valdés, Lourdes. (2009). "Sartre: La conciencia como libertad infinita". Tópicos (México), (37), 09-29. Recuperado de: http://www.scielo.org.mx/scielo.php?script=sci_arttext\&pid=S018866492009000200001\&lng=es\&tlng=es. última revisión: 25/10/19, p. 36.
} 
entonces, es en este momento en el que se da cuenta, se ha dado cuenta, que ser libre es cargar con una gran responsabilidad, ya que cada acción o decisión que toma lo afecta directamente; entonces la libertad, más que ser algo positivo, se convierte en una condena, en un sentimiento afligido existencialista continuo de su propia vida, "el despertar de la libertad, la concienciación del carácter irrevocable de la vida, ver la vida en nuestro mayor limite"?

En este sentido, la libertad es la esencia del hombre, y como parte de él, lo que resulte es su responsabilidad en cualquiera de sus ámbitos. En este sentido, la libertad para Sartre no se da de manera contingente, es decir, que a veces puedes ser libre y a veces no, sino que ésta se da de manera continua y constante.

Sin embargo, la libertad se da tanto en la dimensión individual como en la social, en las cuales se van presentado situaciones, en el ámbito social, que no le permite ser totalmente libre, porque hay un orden establecido basado en leyes y normas, las cuales disminuyen las posibilidades en la libertad del hombre. "Cuando decimos que el hombre se elige, entendemos que cada uno de nosotros se elige, pero también queremos decir con esto que, al elegirse, elige a todos los hombres".

Otra de las limitaciones que tenemos los seres humanos son las instituciones, ya que éstas buscan su propio interés personal, dejando de lado la libertad de los demás, atrofiándola, haciéndoles creer que deber sacrificar su libertad, por un bien común y de necesidad básica.

Por lo que, surge la pregunta ¿debemos sacrificar lo que deseamos hacer con nuestra libertad por el bien de los demás?, Sartre tenía una respuesta antes de adelantarse a decir que sí. Hay que entender que debemos tratar de que todo lo que decidamos lo hagamos desde la razón, pero nunca dañando a los demás.

Por ello, para entender esto, es necesario saber que la libertad la cual señala Sartre, es siempre una posibilidad de actuar, una posibilidad de decisión, pues al

\footnotetext{
7 Varela, Cristián, (2009). 'La institución en la dialéctica de Sartre', en el Coloquio “L’héritage de Georges Lapassade" Universidad de Paris VIII, recuperado de: http://cristianvarela.com.ar/textos/institucion-ensartre., p. 56.

${ }^{8}$ Sartre, Jean- Paul (1990) El existencialismo es un humanismo, Op. Cit, p. 11.
} 
mismo tiempo, es la creación de nuestra esencia. Así aparece el sentimiento de angustia, ya que cuando se elige, se está en la posibilidad de que, si ésta fue una elección correcta o positiva, "la posibilidad de que podría haber mejorado mi propia existencia eligiendo otro posible" y por ello, siempre se tendrá la duda de que lo que hemos elegido es correcto o no, o nos beneficia más que la elección de otra posibilidad. Por lo que toda la vida debemos estar ante esta incertidumbre, en cada paso que vamos dando. En ese sentido, para Sartre, la libertad se da como una especie de "pago" por la libertad que se es dada, la certeza del poder de elección que es siempre. "El existencialista suele declarar que el hombre es angustia. Esto significa que el hombre que se compromete y que se da cuenta de que es no sólo el que elige ser”. ${ }^{\text {Io }}$

\section{La libertad individual y la libertad en lo social:}

La libertad para Sartre se convierte en el centro de la vida del hombre como la confirmación de la existencia, estar consciente de que se es libre es el paso para que cada uno de nosotros pueda hacerse y rehacerse a sí mismo, y que, al mismo tiempo, es darse cuenta de la existencia del otro; en este sentido se crea el contacto con el yo y después en el mundo, con el otro. Para reconocer la presencia del otro y la de uno mismo es necesaria la conciencia, la cual sólo se crea a sí misma por medio de las elecciones del hombre. En este sentido la conciencia, para Sartre, es sólo una posibilidad, como aquello que puede ser, o no ser; la diferencia radica en que, en el ser humano, tiene esta posibilidad de poder auto reconocerse, esta diferencia es la que hace al hombre realmente libre. Es por ello que se abren una multitud de caminos donde el individuo debe ser capaz de elegir, "aquí aparece ya la importancia de la dimensión humana que se caracteriza por ser dueña de su destino". ${ }^{11}$

El hombre tiene una esencia que debe construir a lo largo de su vida, desde el momento en que nace, por eso, "para ser totalmente libre de determinaciones, lo

\footnotetext{
${ }_{9}$ Rodríguez García J. L. Op. Cit, p. 95.

${ }^{10}$ Sartre, Jean- Paul. (1990). El existencialismo es un humanismo, Op. Cit, p. 18.

${ }^{11}$ Ibíd. p. 52.
} 
primero que Sartre debe abolir es la propia esencia”, ${ }^{12}$ ya que el hombre no está determinado por algo así y no tiene una esencia previa, es decir, que a lo largo de su existencia se la irá creando, por ello en ese sentido él mismo será quien se crea y decide el rumbo su existencia, y así es que se da esta parte de la libertad que es individual.

Para Sartre, es necesaria la división entre la libertad individual y la libertad social, ya que es la que determina, en primer lugar, el giro que da su pensamiento existencialista y en segundo, porque muestra la manera en que nuestra libertad se manifiesta con el mundo. En este mismo sentido, la libertad individual, se da cuando somos conscientes de que somos libres y tenemos el poder de elegir. "Y cuando decimos que el hombre es responsable de sí mismo, no queremos decir que el hombre es responsable de su estricta individualidad, sino que es responsable de todos los hombres" ${ }^{13}$ La libertad, en lo social, surge cuando el individuo, y bajo la conciencia, se da cuenta de la presencia del otro; ésta es en la que Sartre pone énfasis en que su compromiso con el otro y su encuentro positivo con este cambia su perspectiva, pues se da cuenta que no sólo su propia existencia basta para poder ser libre, sino que debe tener en cuenta al otro, en este sentido es que cambia la tarea del existencialismo a no únicamente quedarse en la dimensión individual, sino desde una social, de esta manera el individuo, al verse influido por la presencia del otro, ya que cuando uno elige no solo su decisión será para sí mismo, sino que en cada elección, está eligiendo por los demás y por eso sus daciones tienen repercusiones en la vida de los demás, "Así, nuestra responsabilidad es mucho mayor de lo que podríamos suponer, porque compromete a la humanidad entera". ${ }^{14}$ Por consiguiente alguien que lleva su libertad en conciencia puede ver que la capacidad de elegir se ve limitada, ve al otro como algo que no puede ser dominado por él; su individualidad e identidad propia, le permite querer y tomar decisiones que le pueden llegar a afectar:

Esa sombra móvil que es el Otro y que se resiste a ser dominada por mí en la medida en que yo me resisto a ser subyugada por él: mi conciencia quiere conocerte, almacenar tu imagen en

\footnotetext{
12 Varela, Cristián. (2009). Op. Cit., p. 116.

${ }^{13}$ Sartre, Jean- Paul. (1990). El existencialismo es un humanismo, Op. Cit, p. 11

14 Ibid., p. 12.
} 
su interior, por decirlo de alguna manera clara, pero tú te resistes porque no eres un objeto mudo, sino un objeto que quiere ser sujeto, es decir, actividad. ${ }^{15}$

Es por eso que aparece el conflicto, ya que el otro siempre quiere hacerse de la libertad de los demás, porque no se puede llegar a dominar al otro, porque él, bajo su propia conciencia, tiene el poder de elegir y decidir, sin embargo, nunca puede estar totalmente a salvo. Así es como surge el sentimiento de angustia, cuando el otro intenta quitar mi esencia y lo que me hace ser yo, para convertirlo en suyo, el otro pretende ponerse en mi lugar.

\section{La libertad en las sociedades contemporáneas}

En su momento Sartre expresó el desespero y la desesperanza que vivió y odió tanto en las dos guerras mundiales, algo que marcaría su vida y su pensamiento, por lo que, hoy podríamos decir que el pensamiento de Sartre ya no tiene sentido, ya que no podemos situarlo en nuestro tiempo; la idea de libertad que formuló solo se podía entender de acuerdo a su contexto, su pensamiento existencialista devino de la idea de sentirse solo en el mundo, sentimiento provocado por la desolación que se generó como resultado de la experiencia vivida en Europa durante la primera y segunda guerras mundiales. Su pensamiento refleja la política y la ideología de ese momento, que, sin duda, remarcó los limites ontológicos del individuo y la existencia.

La primera guerra mundial, despertó en Sartre una visión política de izquierda, lo hizo darse cuenta de que los sucesos, que habían ocasionado las guerras, devenían de disputas e inconformidades que la burguesía provocaba y que eso solo llevaba un impacto negativo con los más débiles, con ello, escribirá más tarde, con una contundencia que sorprende, que su odio a la burguesía no se extinguiría jamás: "es la civilización que ha desembocado en la ruina y la desolación”. ${ }^{16}$

\footnotetext{
${ }^{15}$ Sartre, Jean- Paul (1990) El existencialismo es un humanismo, Op. Cit, p. 32.

16 Ídem, p. 16.
} 
Ahora bien, ¿cómo posicionar sus obras literarias como una nueva forma de ver el mundo? su pensamiento refleja todo lo que habría de referenciar a la política y la ideología de ese momento que, sin duda remarcó los límites ontológicos del individuo y la existencia.

En El existencialismo es un humanismo, hace énfasis, Sartre, en que resultaba importante más generar, que en la existencia se diera el paso de una libertad individual a una libertad que dependería de todos. Su preocupación por poder construir una libertad, que además fuera entendida colectivamente, indica la obligación de ser responsables más allá de nuestra libertad individual.

Según Milos Millak, Sartre, en sus obras filosóficas, expresó su preocupación por la constante alineación del hombre moderno, que sugiere ésta pérdida de la libertad y la individualidad para integrarse a la sociedad. Por eso para Sartre, "su vida entera se caracterizó por la incansable búsqueda de los auténticos valores humanos y del sentido verdadero de nuestra existencia". ${ }^{17}$

Estos valores, de acuerdo a Sartre, los cuales puedan guiarnos hacia una moral existencialista, basados en la responsabilidad que se tiene frente al otro. "Así soy responsable para mí mismo y para todos, y creo cierta imagen del hombre que yo elijo; eligiéndome, elijo al hombre". ${ }^{18}$

Si recordamos, Sartre era parte de la escuela de los existencialistas ateos, por lo que, para él, no hay tal existencia de Dios. Por lo que, el ser humano como ser racional, tuvo que crear leyes y normas que le permitieran desarrollarse con los demás individuos.

El existencialismo se opone a decididamente a todo tipo de moral laica que quisiera suprimir a Dios con el menor gasto posible [...] Dios es una hipótesis inútil y costosa [...] sin embargo para que haya una moral, una sociedad son necesarios algunos valores a priori. ${ }^{19}$

Por lo que establece una moral que esté de acuerdo con la idea de la libertad individual, que sea la que guíe los actos, y aunque, no totalmente por mera intuición

\footnotetext{
${ }_{17}$ Millak Bijelic, Milos. (2005). Cien años del nacimiento de Sartre (1905-2005), Chile, p. 40.

18 Sartre, Jean- Paul, El existencialismo es un humanismo, Op. Cit, p. 15.

19 Ídem, p. 39.
} 
del sujeto, sí como una moral que esté guiada hacia la moral que se establece como un acuerdo por los miembros de una sociedad, más no guiada por las normas religiosas que se imponen como las que se 'deberían' seguir. Y aunque no se habla de una enajenación como tal, acerca de la moral propuesta por la religión, ésta sí limita la libertad. Se quita al individuo y a sus valores, que son dados a priori para, por medio de acuerdos creados por los hombres, dirigir al individuo.

Y aunque hoy en día la religión sigue siendo parte de la vida cotidiana y está muy presente, aún en todas partes, sin embargo, ya no tiene el mismo impacto que tenía hace tiempo y, en especial, en el contexto histórico en el que se encontraba Sartre, donde la religión poseía gran peso en las decisiones que las personas tomaban, es por ello que Sartre se refiere a una libertad que pueda ser un ejercicio individual emancipador, que pueda guiar al individuo, a su libertad individual originaria.

Hoy en día la idea de un existencialismo sartreano radicaría en el acto de emancipación, el cual lo presenciamos mediante la liberación del individuo de la opresión que las instituciones que se imponen en diversos ámbitos de la sociedad como la escuela, la iglesia y el estado.

Sartre fue anarquista, por lo que, su pensamiento siempre estuvo guiado a la idea de una mejor sociedad, que no está encadenado por lo social, lo político y económico. De esta manera, se hace reflexión sobre nuestro alrededor y la forma en cómo las diferentes instituciones a lo largo de nuestra vida se van imponiendo. "Sartre cree que los seres humanos podrían elegir por sí mismos su propia libertad, un 'serpara-sí que no está encadenado por lo social, funciones políticas y económicas impuestas sobre ellos”. ${ }^{20}$

\footnotetext{
${ }^{20}$ Prini, Prieto. (1992). Historia del existencialismo. Barcelona, Editorial Herder, p. 6.
} 


\section{Las instituciones contemporáneas y la libertad individual (la serie)}

Es necesaria la construcción de una sociedad para que podamos vivir en conjunto, es razonable pensar que un individuo no puede vivir solo, por lo que para Sartre la sociedad es un elemento importante para poder entender el concepto de libertad.

Las instituciones siempre han utilizado el poder que se tiene sobre el hombre, "la actividad humana se realiza a través de instituciones que actúan sobre los individuos para reagruparlos, dividirlos, añadirles o quitarles poder. Para someterlos a reglas y temores" ${ }^{21}$. A las instituciones no les interesa como tal el individuo, la institución provee un bien, o un servicio, que de alguna manera beneficia a la sociedad, sin embargo, la crítica que Sartre había hecho a las instituciones es que éstas, históricamente, se posicionan como el centro de una sociedad,

La institución desea cosificar el cuerpo del hombre, pero lo que hace es quitar todo aquello que lo hace humano y lo transforma para hacer de él lo que quiera, lo utiliza, anula su libertad y lleva a cabo la suya, a costa de la de los demás. ${ }^{22}$

La institución percibe mi cuerpo como un objeto que, de hecho, le resulta tan impenetrable como cualquier otra cosa y que, al igual que su conducta respecto de los objetos en general, él quisiera modelar mi cuerpo y la conciencia que lo anima de acuerdo con el proyecto en el cual radica su propia libertad, anulando con ello la mía. ${ }^{23}$

Esto hace que la libertad de los individuos sea disuelta dentro de las instituciones, ya no se habla de una cohesión entre individuos como una unidad, sino que ahora sólo existen como cantidad sumatoria. Al quitarles su libertad lo único que queda es la masa de individuos que hace posible que la sociedad funcione.

Sin embargo, respecto a esto, la serie, es sólo lo que es cuantitativo y tangible, se ve a la sociedad en general como un conjunto de números que coexiste en un mismo lugar y un determinado tiempo, así mismo no hay una relación entre los

\footnotetext{
${ }^{21}$ Rodes, Juan. (2012). sitiocero: Existencialismo de Sartre, sp.

${ }^{22}$ Cfr. Delhumeau Arrecillas Antonio, Jean Paul Sartre: a cincuenta años de la crítica de la razón dialéctica, 2011. Universidad Nacional Autónoma de México, Facultad de Ciencias Políticas y Sociales, Centro de Estudios Políticos. Estudios Políticos núm. 25: http://www.scielo.org.mx/pdf/ep/n25/n25a3.pdf, p. 27.

${ }^{23}$ Varela, Cristián, (2009). La institución en la dialéctica de Sartre, Coloquio "L'héritage de Georges Lapassade" Universidad de Paris VIII, recuperado de: http://cristianvarela.com.ar/textos/institucion-en-sartre SP.
} 
individuos ya que esto ocurre con desconocidos entre sí, "la serie se caracteriza por la ausencia de relación social entre sus integrantes, ya que se constituye con sujetos anónimos, desconocidos entre sí, carentes de una mutua interpenetración de sus conciencias: el otro no está en mí, ni deseo que lo esté”. ${ }^{24}$ Esta misma falta de homogeneidad y falta de empatía hacia los demás, es la que hace que no pueda haber una uniformidad para transformar su realidad.

Por ello, para Sartre, la serie es la codificadora del individuo, se convierte en solo uno más de la masa de los individuos, en la que sus circunstancias, en contra de su voluntad, lo llevan a elegir algo que realmente no quiere, pero que debe hacer para vivir dentro de una sociedad, y aunque su libertad si se lleva a cabo, mediante el ejercicio de la elección, se ve atrofiada por una circunstancia externa a él, en la serie se es cosa. "Los pasivos pasajeros que hacen cola esperando el colectivo dependen en su circunstancia de una voluntad ajena, lo cual los reduce a la condición de objeto de una rutina determinada por otros en otro lugar". ${ }^{25}$

De esta manera Sartre pone énfasis en cómo se hace presente la enajenación y la alineación de los individuos, en la cual cada uno debe dejar de lado su libertad para cubrir sus necesidades, su cuerpo se convierte en una herramienta que es usada por los hombres de poder como medios de producción.

El individuo pone al descubierto su cuerpo y, aquí, Sartre observa sin decirlo una enajenación básica de la operación realizada por los socialistas de Estado, en tanto que éstos han buscado hacerse con la praxis corporeizada de los otros por medio de sus inercias colectivizantes y burocráticas. ${ }^{26}$

Aquí aparece su crítica a los medios de producción, en los que reconoce al cuerpo, no como algo individual y propio sino, como algo que ha sido robado y utilizado para un bien común, comunitario, en los cuales se esfuerza por mantener y ser parte de ellos,

\footnotetext{
${ }^{24}$ Ibídem.

${ }^{25}$ Ibid. SP

26 Delhumeau Arrecillas Antonio, Jean Paul Sartre: a cincuenta años de la crítica de la razón dialéctica, 2011. Universidad Nacional Autónoma de México, Facultad de Ciencias Políticas y Sociales, Centro de Estudios Políticos. Estudios Políticos núm. 25: http://www.scielo.org.mx/pdf/ep/n25/n25a3.pdf, p. 29.
} 
"para Sartre, no sólo es el cuerpo individual sino también el comunitario el que aparece como objetivo del congelamiento ante la mirada cosificante". ${ }^{27}$

\section{La crítica marxista:}

Sartre retoma la crítica marxista para dar a entender su preocupación y desdén por los modos de enajenación que las instituciones y el estado provocan, y no podemos encontrar un sentido de individualidad.

Es así como la serie se convierte en la ausencia de conciencia común, el hombre se convierte en solo una fuerza más de trabajo, en este sentido, como deja de ser consciente, deja de ser libre:

Hay una reducción a la condición instrumental y subhumana de fuerza material de trabajo [...] Por su parte, la condición serial del habitante de la ciudad (condición inicial en París de 1789 en el análisis de Sartre) no debería resultar de difícil aprehensión para el hombre de la modernidad tardía, habituado a la soledad de la multitud. ${ }^{28}$

No hay distancia a nuestros tiempos de los de Sartre, el hombre se siente solo y desorientado, porque le hace falta su libertad, que le es arrebatada; no tiene verdadera elección, la alienación se disfraza de libertad, la carencia social es fuerte, y los individuos no se identifican unos con otros. Solo siente que se está en un grupo o en una comunidad porque comparte un mismo espacio, sin embargo; algo que ocurre hoy en día y pasó también en su momento en las guerras mundiales y que pudo presenciar Sartre, es la unificación de la serie, convirtiéndose en un grupo, esto lo hacen mediante la identificación del algo en común, de esta se manera pasa de ser un grupo de individuos, sin conciencia de sí mismos y sin interés de los demás, a ser un grupo que lucha por algo.

De esta manera es que, mediante la unión, el grupo vuelve a tener conciencia de su libertad, "La emergencia de una nueva sociedad en la cual es opuesta a la serie, que advendrá bajo la forma del grupo en fusión, es un punto central en la dialéctica

\footnotetext{
${ }^{27} \mathrm{Ibid}, \mathrm{p} .30$.

${ }^{28}$ Varela, Cristián, (2009). Op. Cit, SP.
} 
sartreana, pues supone el momento en que se sale de la alineación y la cosificación por efecto de la libertad común”. ${ }^{29}$

El grupo se crea a partir de que los individuos se ven amenazados por las distintas instituciones, por la forma de gobierno y porque encuentran en la necesidad de hacerlo para poder seguir viviendo, "un grupo se constituye a partir de una multiplicidad serial que ve amenazada su posibilidad de vivir”, ${ }^{30}$ esto es lo que permite que el grupo dé el paso decisivo para fusionarse.

En el contexto histórico de Sartre, al igual que el nuestro, la fusión del grupo surge cuando la existencia del individuo es amenazada; "Cuando esta causa resulta radicalmente cuestionada, ya sea porque ella misma es amenazada en su existencia (agotamiento de una fuente natural de subsistencia, cierre de una fábrica) o porque se vuelve amenazante (la geografía vuelta contra el hombre, el salario no cubriendo la necesidad)". ${ }^{31}$

Y a partir de ello, puede cambiar la situación de los individuos, como ya lo mencionaba Sartre, las decisiones que tomamos, de alguna manera, tienen repercusión en los otros, entonces también la lucha individual, se convierte en una social, para la superación de distintas adversidades.

Sartre menciona que para la integración y fusión del grupo era necesario que los miembros hicieran una especie de juramento, esto con la finalidad de que como miembro o parte del grupo, se hicieran cumplir las distintas normas de comportamiento que se deben llevar a cabo; aún si éste no quiere cumplirlas, es decir, es necesario acatarlas para poder ser miembro del grupo, en este sentido es que surge la institución, "el juramento 'funda' la institución, pero en sí mismo no es institucional". 32

De esta manera el juramento guía el compromiso individual con el grupo y la institución, porque implica su fidelidad ya que, con certeza, cumplirá con todo

\footnotetext{
${ }^{29} \mathrm{Ibid}$. SP

${ }^{30}$ Ibid. SP.

31 Ibid. SP

32 Ibid. SP
} 
aquello que se le pida que haga, ya que su libertad se encuentra sometida al resultado de que no cambiará de decisión, es así que el juramento se convierte en un salto hacia su propia enajenación. "la primera libertad que se pierde a causa del juramento es la libre voluntad con que el integrante del grupo en fusión, cuando realizaba la praxis común, realizaba su propio deseo". ${ }^{33}$

Entonces ya no se realizan las actividades, porque sean necesarias para luchar por un bien común, sino que ahora se está obligado a hacerlo por la institución por medio del juramento, ya no es una libre actividad. "En el estadio del grupo en fusión el individuo era 'el individuo orgánico' [...] no juramentado, y viviendo su libertad en la praxis común, en la ubicuidad de la libertad; él, el individuo orgánico, es quien se pierde por el juramento" ${ }^{34}$

Por lo que la institución lo que hace es dividir socialmente al grupo, acción en la que se ve la desventaja que otros tienen, frente a los demás que tienen, por así decirlo, un poder infringido sobre ellos.

Cuando estamos siendo libres, de manera individual, nuestra libertad consiste en decidir en el accionar individual, sin embargo, cuando esta libertad está dentro de la institución y al sujeto, se ve así mismo mediante la acción común, está llevando su libertad en su dimensión social, por ello él mismo se coacciona dentro de su grupo, ya que los actos individuales ya no tienen sentido dentro de este, el resultado, depende de uno solo y, al mismo tiempo, es responsabilidad de todos. Sin embargo, en la colaboración en equipo es que se encuentra más en un proyecto colectivo o social y no hace de sí su propio proyecto. "Esta dependencia de la praxis individual respecto del objetivo común no supone una alineación, porque el cumplimiento del objetivo de todos es la síntesis del cumplimiento de las acciones individuales”. ${ }^{35}$

\footnotetext{
${ }^{33}$ Zamora, Álvaro. (2005). “De la libertad según Sartre: fundamentos y alguna inconsistencia”, Rev. Filosófica, Univ. Costa Rica, XLIII Número doble (109/110), 125-131, Mayo-Diciembre 2005, Recuperado de file:///E:/lecturas\%202.2/la\%20libertad\%20en\%20sartre, p. 19.

${ }^{34}$ Varela, Cristián, (2009) Op. Cit, SP.

${ }^{35}$ Ibídem.
} 
Es de esta manera que las instituciones interrumpen el que el individuo haga de sí su propio proyecto, lo enajenan. Al mismo tiempo el poder se ve desde arriba de ellos mismos, existe fuera de ellos; el poder es ejercido de muchas maneras, dentro de un juramento y lo que se ve es, la obligación que se debe cumplir; sin embargo, también se pierde la individualidad cuando el poder se impone bajo amenazas, cuando estas normas no se cumplen, es, cuando éstas se llevan a cabo, lo que se da a cambio es el disfrute de su 'libertad'. Cuando aún con las amenazas esto no se lleva a cabo, entonces lo que se recurre es al terror:

En el plano lógico significa un momento de las fuerzas donde éstas sufren en parte una inversión de sentido, que las vuelve hacia el propio grupo. En principio esas fuerzas actúan como amenaza, pero siempre con algún grado de realización, aunque más no sea bajo la forma del sacrificio que se le pide a cada juramentado, y que éste realiza en nombre de la causa común o la misión grupal. ${ }^{36}$

Es por eso que, en el momento en que el individuo es parte de un grupo, la responsabilidad se vuelve parte de todos como un conjunto, en este sentido lo que le pertenece a uno, le pertenece a todos, "Con esta estrategia se logra subordinar la ontología individual a la existencia grupal: tu ser depende de nosotros enuncia el sacrificio". ${ }^{37}$

Por ello, lo que hace la institución es que, en base al sacrificio de la individualidad que haga el hombre, es un subordinado del grupo; una cosa que está por debajo del poder que es la institución, la ley o incluso, la religión misma.

Hoy en día, en nuestras sociedades, contemporáneas, vemos aún a la religión como parte de la cultura, ya que forma algunas bases y normas de nuestro comportamiento, y esto implicó que, de cierta forma, se diera un cambio en nuestro comportamiento; desde su aparición, la religión hizo posible una nueva forma de vida, pero en este momento, se dio una restricción en la libertad, en el cual se entendió al terror, como una forma de evitar o no hacer notar dicha libertad, en todos sus sentidos para el beneficio de los demás. Esto es con lo que se ha educado a la

\footnotetext{
${ }^{36}$ Ibid. SP

${ }^{37}$ Ibid. SP.
} 
sociedad en la que la libertad se va perdiendo, poco a poco, cuando olvidamos que podemos elegir varios caminos que nos llevarán a ser verdaderamente libres, pero como ello implica necesariamente una responsabilidad, se prefiere estar dentro del grupo o la serialidad, porque se siente, y se está, más cómodo y seguro.

El momento en el que el individuo puede liberarse del grupo, para ocuparse de sí mismo, es cuando se separa de la fusión que tiene con el grupo y retoma su autonomía, sin embargo, esa libertad sólo puede ser encontrada dentro de la libertad social, por lo que las dos dimensiones de la libertad entran en discordancia "La unidad es condición de libertad en tanto permite superar la amenaza que oprime al conjunto serial. Pero la libertad lograda, por ser una libertad común, entra en contradicción con las libertades individuales". ${ }^{38}$

En este sentido es que dentro de las sociedades contemporáneas se vive en una constante lucha entre las dimensiones de la libertad, porque por un lado el individuo anhela ser libre, pero al mismo tiempo está atado a las distintas instituciones que lo obligan a cumplir con el fin que el grupo le dio, en un principio. Es así como nace el grupo institucionalizado, que es el encargado de que, las funciones y el poder se institucionalicen para evitar una regresión a la libertad individual, es decir que se vuelva a la serie.

De esta manera las instituciones se tornan parte indispensable de las sociedades contemporáneas, claro que éstas, permiten que algunas de las necesidades del hombre sean cubiertas, ocultándose debajo del lema de 'por el bien común', sin embargo, su costo es su libertad individual y aún más su alienación; la libertad que ejerce mediante el grupo es manejada por otro, por el poder.

"La libertad ya no reside en el grupo, tampoco en la dimensión de cada acción individual cumplida como función grupal, sino en la praxis común, pero realizada sin soberanía individual, ni plena ni parcial". ${ }^{39}$ La sociedad moderna, ahora mismo, se

\footnotetext{
38 Ibid. SP

${ }^{39}$ Ibid. SP.
} 
conforma con el modo de vida que se tiene hoy en día, donde se prefiere deshacerse para no tomar la responsabilidad que les corresponde.

\section{Conclusiones:}

La libertad tiene dos dimensiones; una individual que representa la responsabilidad de poder elegir algo en nuestro día a día y, la dimensión social, en la cual las decisiones que se toman, ya no sólo impactan en mí, sino que también directamente en los demás. Por eso era fundamental para Sartre recordar la importancia del impacto de nuestras decisiones, y la libertad viene siendo la constitución del individuo como ente, donde no existe Dios, por lo que encontramos una libertad radical. Para él, el hombre es quien construye su propia realidad, mediante sus acciones y decisiones, además de que la única parte innegable del individuo es su propia libertad esto, para Sartre, es el punto determinante de su teoría existencialista.

En este sentido es que Sartre nos lo enseña, es que el hombre por medio de su razón, la internalización y reflexión sobre nuestras acciones y lo que hacemos, es lo que nos permite poder llevar a cabo una libertad responsable. Sin embargo, el hombre constantemente está bajo el sentimiento de angustia, por el no poder saber si lo que ha elegido es lo correcto o si ello puede llegar a afectar a los demás.

Para Sartre, el hombre tiene limitantes en tanto que su libertad se encuentra con la de otro individuo, en este sentido es que no podemos hacer lo que queramos. $Y$ a partir de esta idea es que surge una moral, que nos ayuda y sirve para establecer los límites de la libertad y para poder señalar lo que está bien y lo que está mal, por ello, es que el existencialismo se convierte también en una moral, la que se convierte en un ideal utópico, para Sartre.

El hecho de vivir nuestra libertad no implica que podamos hacer lo que queramos, sino que debemos elegir lo que queramos, en sentido, de nuestras circunstancias esto, como forma de poder elegir mediante la realidad objetiva que se nos presenta. La falta de libertad individual hace que el individuo esté atado a la 
institución, de manera que no puede ver otros caminos para él, y bajo la institución él es visto como un simple número o elemento más, por ello para salir de este círculo, según Sartre, es necesario que todos los individuos se unan para poder derrocar a la institución, para quitarle todo el pode y de esta manera es que el ser humano es que es realmente libre, y fuera de toda alineación, vuelve a ser autónomo. 